\title{
A importância da utilização de técnicas moleculares no diagnóstico laboratorial de Dengue virus: uma revisão
}

\author{
The importance of using molecular techniques in laboratory diagnosis of Dengue virus: a review \\ La importancia de utilizar técnicas moleculares en el diagnóstico de laboratorio del virus del \\ dengue: una revision
}

Recebido: 05/09/2021 | Revisado: 12/09/2021 | Aceito: 19/09/2021 | Publicado: 20/09/2021

Dacylla Sampaio Costa

ORCID: https://orcid.org/0000-0002-9909-7353 Universidade Federal do Piaú, Brasil E-mail: dacyllasampaio@hotmail.com

Dakson Douglas Araújo ORCID: https://orcid.org/0000-0003-0102-7240 Universidade Federal do Delta do Parnaíba, Brasil E-mail: dacksondouglas@gmail.com

Jaiane Cruz dos Santos

ORCID: https://orcid.org/0000-0002-4939-2565 Universidade Federal do Delta do Parnaíba, Brasil

E-mail: jaiane.cruz30@gmail.com

Higinalice da Silva Pereira ORCID: https://orcid.org/0000-0002-0119-819X Universidade Federal do Delta do Parnaíba, Brasil

E-mail: alice_higina@hotmail.com

Gabriella Linhares de Andrade

ORCID: https://orcid.org/0000-0003-2481-9646 Universidade Federal do Delta do Parnaíba, Brasil E-mail: gabriellalinhares9@gmail.com

Ana Clara Silva Sales

ORCID: https://orcid.org/0000-0003-4978_235X Universidade Federal do Delta do Parnaíba, Brasil E-mail: clarasales02@gmail.com

Nathanael Dos Santos Alves ORCID: https://orcid.org/0000-0001-6945-6282 Universidade Federal do Delta do Parnaíba, Brasil E-mail: santosnathanae155@gmail.com

Ana Indygriani Rodrigues ORCID: https://orcid.org/0000-0003-4070-4048 Universidade Federal do Delta do Parnaíba, Brasil E-mail: indygliane@gmail.com

\begin{abstract}
Resumo
As arboviroses correspondem a doenças transmitidas aos seres humanos pela picada de vetores artrópodes e constituem um crescente problema de saúde pública. Grande parte destes arbovírus estão emergindo e circulando por todo o país, dentre eles, destaca-se o vírus da dengue. Este arbovírus apresenta quatro sorotipos, DENV1-4, dessa forma torna-se importante o uso de técnicas que possam identificar o sorotipo presente. Nesse contexto, o presente estudo trata-se de uma revisão da literatura que tem como objetivo demonstrar a importância do uso de técnicas moleculares no diagnóstico da dengue. Para tal, foram realizadas buscas de artigos científicos nas bases de dados PubMed, LILACS, SciElo e Google acadêmico. Verificou-se que o uso da técnica molecular de RT-PCR e suas variações são altamente importantes para a deteç̧ão viral, bem como para diferenciação dos sorotipos circulantes. Logo, está é uma técnica que tem vantagens no diagnóstico da dengue, pois apresenta boa sensibilidade, especificidade e reprodutibilidade. Portanto, observa-se que o diagnóstico molecular laboratorial contribui positivamente para o isolamento viral, além de garantir a identificação do genótipo circulante e assim garantir qual sorotipo prevalece em determinada localidade. Essas vantagens de isolamento, contribuem para o controle epidemiológico e serve para alerta as autoridades sanitárias a promover medidas preventivas e de controle a essa doença.
\end{abstract}

Palavras-chave: Arbovírus; Dengue; Biologia molecular; Reação em Cadeia da Polimerase. 


\begin{abstract}
Arboviruses correspond to diseases transmitted to humans by the bite of arthropod vectors and constitute a growing public health problem. Most of these arboviruses are emerging and circulating throughout the country, among them, the dengue virus stands out. This arbovirus has four serotypes, DENV1-4, so it is important to use techniques that can identify the present serotype. In this context, this study is a literature review that aims to demonstrate the importance of using molecular techniques in the diagnosis of dengue. To this end, searches were performed for scientific articles in the PubMed, LILACS, SciElo and Academic Google databases. It was found that the use of the molecular technique of RT-PCR and its variations are highly important for viral detection, as well as for the differentiation of circulating serotypes. Therefore, this is a technique that has advantages in diagnosing dengue, as it has good sensitivity, specificity and reproducibility. Therefore, it is observed that laboratory molecular diagnosis contributes positively to viral isolation, in addition to ensuring the identification of the circulating genotype and thus guaranteeing which serotype prevails in a given location. These isolation advantages contribute to epidemiological control and serve to alert health authorities to promote preventive and control measures for this disease.
\end{abstract}

Keywords: Arboviruses; Dengue; Molecular biology; Polymerase Chain Reaction.

\title{
Resumen
}

Los arbovirus corresponden a enfermedades transmitidas al ser humano por la picadura de artrópodos vectores y constituyen un creciente problema de salud pública. La mayoría de estos arbovirus están emergiendo y circulando por todo el país, entre ellos destaca el virus del dengue. Este arbovirus tiene cuatro serotipos, DENV1-4, por lo que es importante utilizar técnicas que puedan identificar el presente serotipo. En este contexto, este estudio es una revisión de la literatura que tiene como objetivo demostrar la importancia del uso de técnicas moleculares en el diagnóstico del dengue. Para ello, se realizaron búsquedas de artículos científicos en las bases de datos PubMed, LILACS, SciElo y Academic Google. Se encontró que el uso de la técnica molecular de RT-PCR y sus variaciones son de gran importancia para la detección viral, así como para la diferenciación de serotipos circulantes. Por tanto, esta es una técnica que tiene ventajas en el diagnóstico del dengue, ya que tiene buena sensibilidad, especificidad y reproducibilidad. Por tanto, se observa que el diagnóstico molecular de laboratorio contribuye positivamente al aislamiento viral, además de asegurar la identificación del genotipo circulante y así garantizar qué serotipo prevalece en una localización determinada. Estas ventajas de aislamiento contribuyen al control epidemiológico y sirven para alertar a las autoridades de salud para promover medidas de prevención y control de esta enfermedad.

Palabras clave: Arbovirus; Dengue; Biología molecular; Reacción en Cadena de la Polimerasa.

\section{Introdução}

As arboviroses são doenças transmitidas aos seres humanos pela picada de vetores artrópodes e constituem um crescente problema de saúde pública. Nos últimos anos, a incidência destas arboviroses aumentou largamente devido às alterações climáticas, ambientais e populacionais que favoreceram à amplificação e transmissão viral. Estes fatores facilitaram a emergência e reemergência destes patógenos, resultando em impacto na morbidade e mortalidade, sobretudo em regiões endêmicas, como países de climas tropicais e subtropicais (Go; Balasuriya; Lee, 2014; Lopes; Gubler, 2002; Weaver; Reisen, 2010; Terzian et al., 2011).

No Brasil, grande parte destes arbovírus estão emergindo e circulando por todo o país, dentre eles, destaca-se o Dengue virus (DENV), pertencente à família Flaviviridae e gênero Flavivirus, o qual é responsável por gerar um grande impacto econômico e social, com uma estimativa de 390 milhões de infecções por ano (Bhatt et al., 2013). O DENV apresenta quatro sorotipos (DENV1-4) que estão amplamente distribuídos em todo o mundo, inclusive no Brasil, onde houve relatos da primeira circulação desde a década de 80 (Cavalcanti et al., 2011). Nos últimos anos, vários estudos demonstraram a cocirculação dos quatro sorotipos de DENV em várias regiões do país, o que caracteriza uma situação de hiperendemicidade na região e favorece o desenvolvimento de epidemias, bem como a possibilidade da ocorrência de formas graves da doença. Vale destacar que a infecção ocasionada por qualquer um dos quatro sorotipos pode resultar em uma série de manifestações clínicas, que variam de casos assintomáticos ou febres autolimitadas, e até mesmo extrapolando para doenças hemorrágicas severas podendo levar a óbitos (WHO, 2009; Silva et al., 2021; Nozawa; Linhares, 2014).

De acordo com dados do Ministério da Saúde, no ano de 2019, a taxa de incidências de casos de DENV no Brasil foi de 735,2 casos por 100 mil habitantes, com cerca de 1.544.987 notificações de casos prováveis. Quando se discorre sobre regiões brasileiras afetadas, a região Sul é descrita com 165,2 casos por 100 mil habitantes, seguido da região norte com 195,8 
casos por 100 mil habitantes. Adicionalmente, em terceiro, o Nordeste com 376,7\% a cada 100 mil habitantes, sudeste com 1.159,4 casos/100 mil habitantes e em última análise a região Centro-oeste com 1.349,1 casos por 100 mil habitantes (Ministério da Saúde, 2020).

Por outro lado, para o ano de 2020, o Ministério da Saúde notificou um total de 971.136 casos prováveis de DENV, dos quais a taxa de incidência foi de 462,1 casos/100 mil habitantes na região brasileira. Dessa forma, observa-se que houve uma diminuição de casos e até mesmo de incidência quando comparado ao ano anterior, tal redução pode ser atribuída a mobilização nacional para o combate ao SARS-CoV2 o que pode ter ocasionado uma subnotificação nos casos de arboviroses, visto que as observações dos primeiros boletins levavam a aumento de casos (Ribeiro et al., 2020). Dos casos notificados por região, a região Norte apresentou uma incidência de 114,0 casos por 100 mil habitantes e seguido da região Nordeste com 258,6 mil habitantes. Adicionalmente, a região Sudeste, Sul e Centro-Oeste com respectivamente, 373,2, 931,3 e 1.187,4 casos por 100 mil habitantes (Ministério da Saúde).

Baseado em vários estudos realizados, suspeita-se que casos por DENV sejam subestimados e erroneamente diagnosticados. Tais fatos são consequência das manifestações clínicas iniciais que são semelhantes a outros arbovírus, bem como pelo desenvolvimento de reações cruzadas que advém da baixa especificidade dos testes sorológicos, o que dificulta o diagnóstico diferencial (Heinz; Stiasny, 2012).

Diante das informações apresentadas, as técnicas moleculares, como a técnica de RT-PCR (do inglês "Reverse Transcriptase - Polymerase Chain Reaction") e suas variantes, bem como o desenvolvimento de novos protocolos, devem ser implementados e aperfeiçoados para auxiliar na identificação correta e específica de DENV, facilitando o diagnóstico precoce (Heinz; Stiasny, 2012). Além disso, a detecção molecular dos sorotipos virais do DENV (1-4), proporcionam um monitoramento da introdução e possível circulação, como também a caracterização deste arbovírus. Assim, tais dados poderão contribuir na detecção dos casos, informando o real estado epidemiológico, para que, seja dado um melhor direcionamento às autoridades de saúde a ponto de traçar estratégias de prevenção e controle, mais seguras e eficazes, objetivando a diminuição das taxas de incidências e surgimentos de novas epidemias, bem como auxiliar no manejo clínico adequado do paciente. Baseado nisso, o presente estudo tem como objetivo identificar a importância da utilização destas técnicas direcionadas à biologia molecular como meio diagnóstico de dengue.

\section{Metodologia}

O presente estudo trata-se de uma revisão documental, descritiva e de abordagem qualitativa (Rodrigues et al., 2020; Araújo et al., 2020). Para alcançar o objetivo previamente estabelecido, foram utilizados sites nacionais e internacionais de publicação de artigos científicos, a saber: National Library of Medicine (PubMed), Literatura Latino-americana e do Caribe (LILACS), Scientific Electronic Library Online (SciELO) e Google Acadêmico. A busca das publicações deveria apresentar a utilização de técnicas de biologia molecular no diagnóstico de DENV, dando enfoque à sua eficácia no que se refere a sensibilidade e especificidade na deteç̧ão viral. Nesse sentido, o presente estudo deve responder à pergunta norteadora acerca da "importância do diagnóstico molecular na virologia, como forma de detecção precoce de DENV".

Para a seleção dos artigos científicos foi utilizado os seguintes critérios de inclusão: artigos publicados em inglês ou português, com resumos disponibilizados na base de dados selecionada e com período de publicação com intervalo de cinco anos, respectivamente, 2009 a 2020. Por outro lado, como critérios de exclusão, foram excluídos artigos de revisão de literatura, trabalhos de conclusão de curso, dissertações de mestrado, testes de doutorado, e aqueles que não apresentaram informações relevantes acerca do tema em destaque.

Além disso, para o desenvolvimento da pesquisa empregou-se descritores para a busca das publicações, sendo estes "Vírus da Dengue", "Biologia Molecular", "PCR” e "RNA-Seq". Os mesmos também foram empregados em inglês, para a 
busca de publicações internacionais. Após a seleção, foi desenvolvido um levantamento de estudos, em que se realizou a leitura inicial dos títulos para seleção prévia.

Em detalhes, para a seleção dos artigos, os critérios foram divididos em: identificação, triagem, elegibilidade e inclusão. No processo de identificação, os artigos no banco de dados foram selecionados e os que apareceram em duplicata foram removidos. Na triagem, os artigos foram selecionados de acordo com os critérios de inclusão pré-estabelecidos.

Para a elegibilidade das publicações, cada título e resumo foi lido detalhadamente para confirmar a relevância e adequar ao tema em estudo desta pesquisa. Ao final, foram selecionados os artigos lidos na íntegra e que apresentavam informações que pudessem compor a presente revisão descritiva. No Diagrama 1 pode-se observar como foi desenvolvida a coleta de dados.

Diagrama 1 - Diagrama da seleção dos dados para análise do presente estudo.

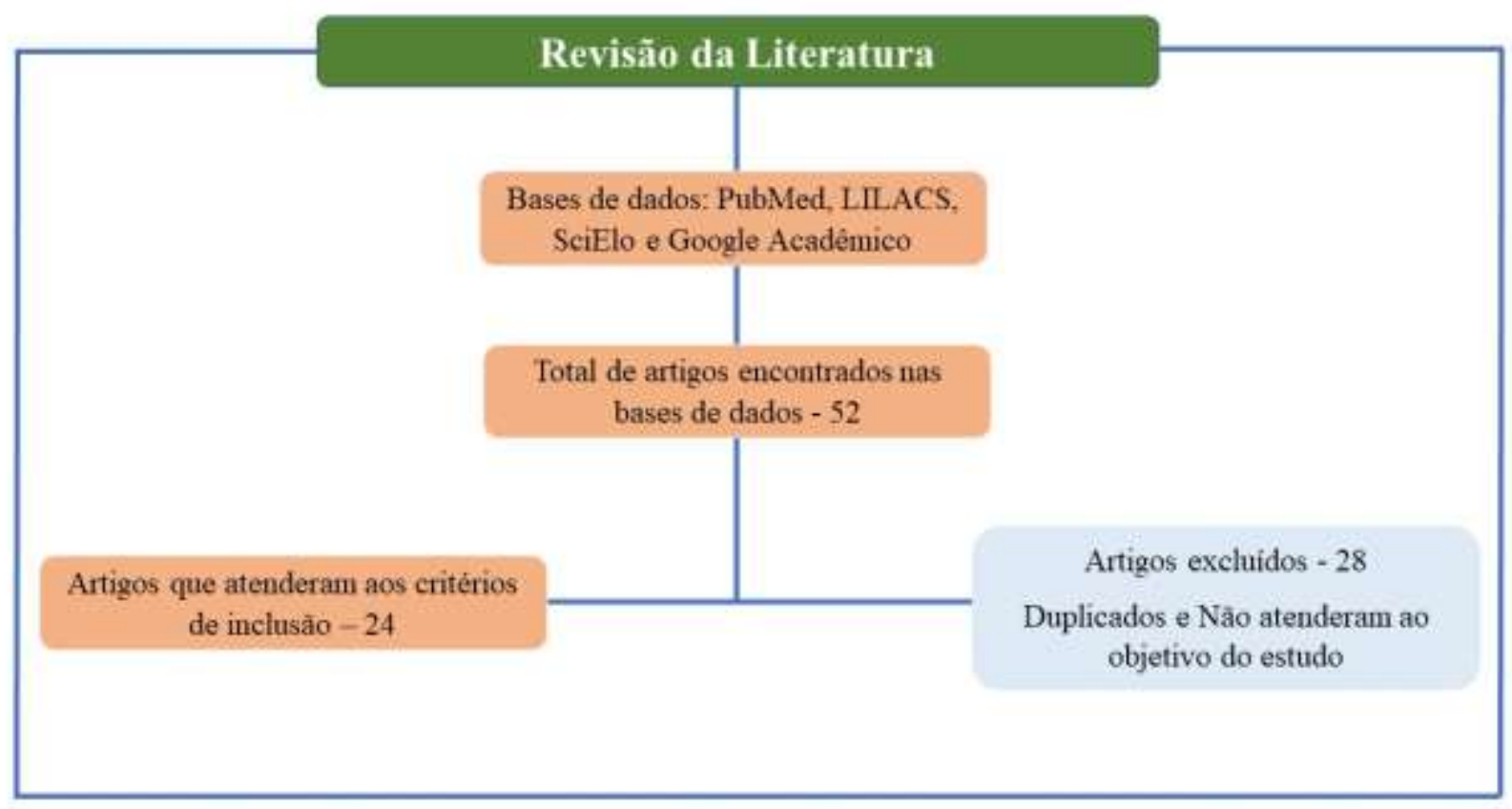

Fonte: Autores (2021).

\section{Resultados e Discussão}

A partir da busca de dados na literatura, foram encontrados 52 artigos nas bases de dados selecionadas, dos quais 26 foram excluídos por não atenderem aos critérios pré-estabelecidos e/ou por não terem dados suficientes para compor a revisão. Após leitura integral, 2 artigos foram excluídos, sendo então selecionados 24 artigos para a revisão descritiva. Na maioria dos artigos selecionados, a metodologia de escolha foi a PCR convencional, utilizando amostras de pacientes com sintomatologia sugestiva de DENV. Tal metodologia é descrita como a técnica padrão ouro para detecção do genoma viral dos quatro sorotipos virais de DENV.

No que concerne a pesquisa nas bases de dados descritas anteriormente, demonstrou-se que os artigos direcionados ao estudo de Dengue vírus concatenados à detecção através de métodos moleculares enfatizaram de forma constante e satisfatória a importância da metodologia utilizada, bem como aplicada a doença em estudo. 
A identificação precoce e específica das arboviroses como DENV, através de métodos diagnósticos rápidos e confiáveis é importante para melhorar não apenas o diagnóstico clínico e diferencial, mas também auxiliar na investigação e monitoramento da circulação destes, permitindo a identificação correta e precoce, com a finalidade de evitar possíveis epidemias e progressão dos sintomas para casos graves (Guzman et al., 2010; Moreli, Costa, 2013; Guzman; Harris, 2015; Seshan et al., 2017; Santiago et al., 2018).

As técnicas moleculares são uma alternativa para um diagnóstico precoce, confiável, sensível e específica, através da detecção de genomas virais durante a fase aguda, sendo bastante utilizados em laboratórios de referência e de pesquisa (Peeling et al., 2010; Moreli, Costa, 2013). A identificação correta dos arbovírus é dificultada pela apresentação de sintomas inespecíficos, durante a fase aguda da infecção, e pela cocirculação de diferentes arbovírus. Dessa forma, um diagnóstico específico, através de RT-PCR, constitui uma ferramenta útil para a identificação correta destas infecções (Bronzoni et al.,2005; Heinz; Stiasny, 2012).

Dentre os vários protocolos implementados, destaca-se RT-PCR convencional, tal metodologia consiste na amplificação do genoma viral presente em amostras clínicas de soro, LCR, sangue, plasma, tecidos, saliva e urina, para isso existem inúmeros protocolos específicos para cada arbovírus. Esse método possui alta sensibilidade e especificidade, e possibilita amplificar uma sequência específica do RNA viral utilizando iniciadores específicos para cada região genômica (Lanciotti et al., 1992; Bronzoni et al.,2005; Barkham et al., 2006; Johnson et al., 2012; Guzman; Harris, 2015;). Mais recentemente, houve a implementação da RT-PCR em tempo real que apresenta uma maior sensibilidade, maior rendimento, menor risco de contaminação e a possibilidade de quantificação em tempo real do cDNA amplificado em cada ciclo, frente ao método convencional (Chao; Davis; Chang, 2007; Santiago et al., 2018).

Em aproximadamente $92 \%$ dos estudos a metodologia padrão utilizada foi a RT-PCR e suas variações, além da implementação de outras técnicas direcionadas a análise em biologia molecular. Em detalhes, a RT-PCR convencional foi utilizada, exclusivamente, por 5 dos 19 estudos (cerca de 26\%) e os estudos subsequentes utilizaram a mesma metodologia, contudo utilizaram-na em associação com outras metodologias de biologia molecular para suporte na detecção e/ou para identificação de possíveis variações genéticas, a exemplo: RT-PCR Semi-nested e multiplex (Terzian et al., 2011; Johnson et al., 2012; Sesham et al., 2017; Suwanmanee et al.,2018; Boga et al., 2019; Cai et al., 2020; Eldigail et al., 2020).

O DENV apresenta quatro sorotipos que são filogeneticamente subdivididos em diferentes genótipos de acordo com sua variedade nucleotídica e linhagens (Ratnam et al., 2013; Prajapati et al., 2020). Estes genótipos apresentam diferenças genéticas de aproximadamente 3\% no nível de aminoácidos e 6\% ao nível de nucleotídeos e são de grande importância para desenvolvimento de virulência e gravidade das manifestações clínicas. Com base em caracterizações moleculares das regiões dos genes M, E e NS1, foi determinada uma diversidade genética entre os DENV, sendo reconhecidos cinco genótipos para o DENV-1, seis genótipos para o DENV-2, cinco para o DENV-3 e quatro genótipos para o DENV- 4 (Rico-Hesse, 2003; Sim; Hibberd., 2016; Fares et al., 2015).

Diversos estudos relataram que o sorotipo DENV-2 foi apontado como o mais prevalente em vários surtos nas Américas e epidemiologicamente tem sido descrito como o mais relevante em todo o mundo. Quanto a virulência, o genótipo Asiático do DENV-2 destaca-se por sua grande associação ao desenvolvimento de manifestações hemorrágicas, em comparação aos outros genótipos (Weaver; Vasilakis, 2009).

Em alguns trabalhos, as amostras que apresentaram resultado positivo por PCR convencional foram encaminhadas ao método de sequenciamento de SANGER, essa metodologia de sequenciamento filogenético permite detectar o genótipo ou linhagem viral presente na amostra, bem como possíveis mutações que possam favorecer o desenvolvimento de cepas mais virulentas que podem predispor o desenvolvimento de manifestações graves (Mendonça et al., 2018; Queiroz et al., 2020). Um 
dos estudos identificou a circulação do genótipo I de DENV-3, em amostra de soro de um paciente que voltava de viagem a Cingapura, através do sequenciamento de todo o gene da proteína de envelope (Mendonça et al., 2018).

Novas técnicas, como o sequenciamento de nova geração (Next Generation Sequencing - NGS) foi utilizado em 5 estudos na identificação de mutações a nível de nucleotídeos e aminoácidos (Perry; Tai, 2018; Jerome et al., 2019; Kar et al., 2019; Cai et al., 2020; Queiroz et al., 2020). A diferença desta técnica para as demais baseia-se detecção de todas as alterações existentes no DNA sequenciado, por meio de softwares de computadores, comparando com os DNAs de amostras controle. No estudo realizado por Kar (2019) foi possível identificar 64 isolados clínicos de DENV, principalmente DENV-2, identificado como o mais virulento, o que corrobora com as manifestações clínicas graves e atípicas apresentadas pelos pacientes positivos para o sorotipo detectado, onde os maiores títulos virais foram associados a isolados de pacientes com dengue com sinais de alerta e casos graves de dengue. Análises filogenéticas com base no sequenciamento do genoma completo caracterizaram as cepas circulantes de DENV-2 para o genótipo Cosmopolita. Com esta técnica foi possível identificar diferentes mutações a nível de aminoácidos, assim evidenciando a biologia molecular como uma área relevante na atualidade, principalmente no diagnóstico satisfatório, sensível e específico de DENV, como de outras doenças (Weaver; Vasilakis, 2009).

Diante disso, com a utilização da PCR em associação ao sequenciamento, é possível a detecção dos genomas de DENV e subsequente identificação do genótipo circulantes. Algumas pesquisas têm demonstrado uma associação entre determinados genótipos do DENV e uma maior tendência ao desenvolvimento de formas graves da doença, o que demonstra a importância da aquisição de técnicas que permitam a identificação dos sorotipos virais (Kyle; Harris, 2008).

Além disso, a co-circulação de múltiplos sorotipos de DENV na mesma região representa um risco para ocorrência de gravidade das infecções, visto que o desenvolvimento de dengue grave está diretamente ligado a produção de anticorpos neutralizantes produzidos em uma primeira infecção por um dos sorotipos do dengue. Ademais a infecções simultâneas podem afetar os eventos de recombinação e levar ao surgimento de isolados mais virulentos (Castañeda., 2017; Queiroz et al., 2020; Ahmad et al., 2020). Diante disto, o diagnóstico diferencial, pelo estabelecimento de métodos mais sensíveis, específicos e que detectem uma maior diversidade de linhagens virais circulantes, é de grande importância para distinguir os diferentes genótipos de DENV.

A utilização de variantes da PCR, em destaque a PCR-multiplex, tem como princípio a identificação dos quatro sorotipos virais circulantes de DENV, bem como outros arbovírus circulantes, de maneira simultânea, também permite a detecção de possíveis co-infecções que são marcadas pelo agravamento e desenvolvimento de manifestações graves e atípicas. Esta técnica foi utilizada por $5(10 \%)$ estudos, nos quais foi possível identificar pacientes coinfectados com Dengue e Chikungunya virus, com evolução para manifestações atípicas de gravidade, tais como: encefalite, polineuropatia, alterações hemorrágicas, no qual uma pequena parcela dos casos evoluíram ao óbito (Sucipto et al., 2018; Suwanmanee et al.,2018; Boga et al., 2019; Stubbs et al.,2020).

Outra metodologia atualmente implementada é a Reação em cadeia da polimerase-transcriptase reversa quantitativa, com sigla qRT-PCR (do inglês quantitative Reverse Transcripitase - Polymerase Chain Reaction), que tem como objetivo aprimorar a capacidade de detecção de DENV, por sua alta sensibilidade e especificidade, como também quantificar em tempo real o cDNA viral nas amostras testadas. Para realização desta técnica, podem ser utilizadas duas abordagens, definidas pela utilização de diferentes marcadores: corantes SYBR® Green e sondas TaqMan®. Na primeira, o fluorocromo não é específico para uma determinada sequência de DNA, detectando e ligando-se a qualquer produto de cadeia dupla da PCR, sendo a especificidade da deteç̧ão e quantificação devida à especificidade dos iniciadores. Já a segunda requer um fluorocromo ligado a uma sonda na extremidade 3' do DNA e a presença de um quencher na extremidade 5' com especificidade para uma sequência de DNA e que detecta somente esta sequência em todos os produtos da PCR (Mansuy et al., 2018; Wu et al., 2018). 
A qRT-PCR, também conhecida como PCR em tempo real, essa técnica permite não somente a identificação, como também a quantificação da carga viral, que pode ser correlacionado com a gravidade das manifestações clínicas. Nos estudos analisados, foi verificado a eficiência da técnica a partir de diferentes testes de padronização. Os resultados demonstraram que os valores de CT (Threshold Cycle) dos quatro modelos de sorotipo foram semelhantes em cinco instrumentos de PCR em tempo real. Assim, este sistema fornece um método preciso para detecção e sorotipagem de DENV, que pode ser aplicado em diagnóstico e vigilância epidemiológica (Mansuy et al., 2018; Wu et al., 2018; Mun et al., 2019). Dentre os trabalhos analisados $6(11,5 \%)$ detectaram o genoma viral, assim como determinaram a carga viral, por meio da amplificação do material genético, o que é de grande valia por sua correlação entre gravidade dos sintomas, possibilitando a prevenção e antecipação de evolução grave. (Santiago et al., 2018; Slavov et al., 2019; Gonçalves et al., 2019; Carvalho et al., 2019; Cai et al., 2020).

Os estudos demonstraram uma alta sensibilidade da técnica, o que permitiu a detecção de DENV em amostras consideradas com baixo período de viremia. Este resultado satisfatório confirma a importância da aplicação de várias técnicas direcionadas ao diagnóstico molecular, aumentando a possibilidade de detecção de determinado sorotipo viral de DENV e monitoramento dos pacientes de acordo com a caga viral apresentada. Além disso, estes resultados demonstram a melhoria da sensibilidade e especificidade das novas tecnologias frente as anteriores (Pateu et al., 2013; Sesham et al., 2017; Peeling et al., 2010).

Outros métodos moleculares mostraram-se eficientes, como a amplificação isotérmica de genes mediada por alça (LAMP) descrito como um novo método de amplificação de material genético desenvolvido pela Eiken Chemical Company em Tóquio, Japão. Ele tem como premissa a substituição da PCR devido à sua simplicidade, rapidez, especificidade e relação custo-benefício. O ensaio LAMP de transcrição reversa (RT-LAMP) é uma ferramenta de diagnóstico simples, na qual a reação é realizada em um único tubo, misturando o tampão, os primers, a transcriptase reversa e a DNA polimerase e incubando a mistura a $63{ }^{\circ} \mathrm{C}$ por 30 minutos. Este método, quando comparado ao RT-PCR e ao PCR em tempo real, possui as vantagens da simplicidade da reação e da sensibilidade de detecção. O ensaio LAMP foi desenvolvido como uma valiosa ferramenta de amplificação do material genético para a detecção rápida de doenças infecciosas e atualmente está sendo cada vez mais implementado por vários pesquisadores para identificação rápida de vírus emergentes, como o West Nile virus, dengue virus, Japanese encephalitis virus, dentre outros (Lau et al., 2015; Neeraja et al., 2015).

A sensibilidade e especificidade dos resultados da RT-LAMP foram calculadas e comparadas com o qRT-PCR e ELISA. O RT-LAMP demonstrou alta sensibilidade com o limite de detecção de 10 cópias de RNA para todos os sorotipos. O RNA do vírus da dengue foi detectado em todas as amostras positivas usando RT-LAMP e em nenhuma das amostras foram negativas. O ensaio RT-LAMP tem uso potencial para diagnóstico clínico precoce, sorotipagem e vigilância da infecção por DENV em países endêmicos para esta patologia (Lau et al., 2015; Neeraja et al., 2015).

Os quatro sorotipos de DENV até então identificados podem ser diagnosticados através de metodologias baseadas em biologia molecular, sendo de grande importância para o diagnostico diferencial e precoce, se tornando relevante para o correto manejo do paciente e aplicação de medidas preventivas. Atualmente, as técnicas voltadas para o diagnóstico molecular são consideradas satisfatórias, pois mostram resultados confiáveis nas análises biológicas de diversas amostras, tais como: soro, LCR, sangue, plasma, tecidos, saliva e urina (Barkham et al., 2006; Johnson et al., 2012; Guzman; Harris, 2015).

Os estudos objetivaram diagnosticar o dengue vírus, identificar possíveis coinfecções, detectar a carga viral correlacionado ao desenvolvimento de alterações atípicas, como também agravamento de manifestações graves e, subsequente caracterização da dinâmica viral através de inferências filogenéticas. Os autores afirmaram que, novas mutações no genoma viral, até então não detectadas, podem ser investigadas com o avanço e refinamento das técnicas de biologia molecular, como exemplo o sequenciamento de nova geração e destacam a importância da vigilância contínua da circulação de dengue, através 
de técnicas moleculares, em áreas endêmicas, a fim de obter uma compreensão mais clara da dinâmica da DENV e possíveis alterações no genoma viral.

\section{Conclusão}

Diante das informações apresentadas, a utilização de técnicas voltadas a biologia molecular é de grande relevância para a elucidação da real situação epidemiológica dos casos de dengue e, proporcionam um melhor monitoramento da introdução e possível circulação dos sorotipos deste arbovírus. As técnicas moleculares por apresentarem uma boa sensibilidade e especificidade, são essenciais para o diagnóstico ainda nos primeiros dias de infecção, possibilita a intervenção terapêutica precoce, podendo com isso controlar uma possível evolução para casos graves da doença.

Ademais, conclui-se que a utilização das técnicas variantes e complementares da RT-PCR fornecem informações sobre a evolução e dinâmica viral, o que permite conhecer tanto a virulência dos genótipos circulantes como a diversidade e gravidade das manifestações clínicas de cada sorotipo. Além disso, as técnicas de biologia molecular, também fornecem informações relevantes para as autoridades sanitárias, possibilitando que essas tracem estratégias preventivas e de controle, objetivando a taxa de incidência e surgimento de novas epidemias. Dessa forma, este estudo constata-se a importância de se dispor de técnicas moleculares para o diagnóstico de dengue, até mesmo para garantir informações acerta dos sorotipos circulantes e contribuir com a epidemiologia e assim poder alertar a população acerca dos casos confirmados.

Desta forma, é importante considerar a realização de testes moleculares, visto que algumas outras doenças se assemelham a sinais e sintomas da dengue, como é o caso de Chikungunya e Zika-Vírus. Com uma identificação correta é possível contribuir com um controle de saúde pública para a população em geral, além de abrir portas para mais estudos sobre a relação epidemiológica da dengue. Sendo essa perspectiva possível apenas por conta das técnicas laboratoriais de diagnóstico molecular.

\section{Referências}

Ahmad, F. U., Paul, S. K., Aung, M. S., Mazid, R., Alam, M., Ahmed, S., Haque, N., Hossain, M.A., Paul, S., Sharmin, R., Kobayashi, N. (2020). Cocirculation of dengue virus type 3-genotype I and type 2-Cosmopolitan genotype in 2018 outbreak in Dhaka, Bangladesh. New Microbes New Infect. 33, 100629.

Añez, G., Morales-Betoulle, M. E., Rios, M. (2011) Circulation of diferente lineages of dengue vírus type 2 in Central America, their evolutionary time-scale and selection pressures anlysis. PLoS One, 6(2011), p. e27459.

Araújo, D. D., da Silva, E. C., da Silva Pereira, H., do Nascimento, M. V. S., \& dos Santos, M. P. (2021). A resistência bacteriana frente a antibióticos utilizados no tratamento da gonorreia: uma revisão de literatura. Research, Society and Development, 10(3), e16710313127-e16710313127.

Bang, W. J., Won, M. H., Cho, S. T., Ryu, J., \& Choi, K. S. (2021). A multiplex PCR assay for six Aedini species, including Aedes albopictus. Parasites \& vectors, 14(1), 1-9.

Barcelos Figueiredo, L., Sakamoto, T., Leomil Coelho, L. F., de Oliveira Rocha, E. S., Gomes Cota, M. M., Ferreira, G. P., \& Kroon, E. G. (2014). Dengue virus 2 American-Asian genotype identified during the 2006/2007 outbreak in Piauí, Brazil reveals a Caribbean route of introduction and dissemination of dengue virus in Brazil. PLoS One, 9(8), e104516.

Barkham, T. M., Chung, Y. K., Tang, K. F., \& Ooi, E. E. (2006). The performance of RT-PCR compared with a rapid serological assay for acute dengue fever in a diagnostic laboratory. Transactions of the Royal Society of Tropical Medicine and Hygiene, 100(2), 142-148.

Bhatt, S., Gething, P. W., Brady, O. J., Messina, J. P., Farlow, A. W., Moyes, C. L., \& Hay, S. I. (2013). The global distribution and burden of dengue. Nature, 496(7446), 504-507.

Boga, J. A., Alvarez-Arguelles, M. E., Rojo-Alba, S., Rodríguez, M., de Oña, M., \& Melón, S. (2019). Simultaneous detection of Dengue virus, Chikungunya virus, Zika virus, Yellow fever virus and West Nile virus. Journal of virological methods, 268, 53-55.

Bronzoni, R. V. D. M., Baleotti, F. G., Ribeiro Nogueira, R. M., Nunes, M., \& Moraes Figueiredo, L. T. (2005). Duplex reverse transcription-PCR followed by nested PCR assays for detection and identification of Brazilian alphaviruses and flaviviruses. Journal of clinical microbiology, 43(2), 696-702.

Cai, L., Zhang, H. J., He, F. L., Feng, Y. Y., Hu, S. X., Wang, J., \& Gao, L. D. (2020). Epidemiological and virus molecular characterization of dengue fever outbreak in Hunan province, 2018. Zhonghua liu Xing Bing xue za zhi= Zhonghua Liuxingbingxue Zazhi, 41(12), $2119-2124$. 
Carvalho, F. R., Medeiros, T., de Oliveira Vianna, R. A., Douglass-Jaimes, G., Nunes, P. C. G., Quintans, M. D. S., \& Silva, A. A. (2019). Simultaneous circulation of arboviruses and other congenital infections in pregnant women in Rio de Janeiro, Brazil. Acta tropica, $192,49-54$.

Cavalcanti, L. P., Vilar, D., Souza-Santos, R., \& Teixeira, M. G. (2011). Change in age pattern of persons with dengue, northeastern Brazil. Emerging infectious diseases, 17(1), 132.

Chao, D. Y., Davis, B. S., \& Chang, G. J. J. (2007). Development of multiplex real-time reverse transcriptase PCR assays for detecting eight medically important flaviviruses in mosquitoes. Journal of clinical microbiology, 45(2), 584-589.

de Medeiros Silva, F. C., de Souza Bezerra, H., de Araújo, A. O. C., de Carvalho, L. E. S., \& da Silva, J. A. (2021). Estudo temporal das arboviroses: Uma análise espacial. Research, Society and Development, 10(7), e10910716220-e10910716220.

Eldigail, M. H., Abubaker, H. A., Khalid, F. A., Abdallah, T. M., Musa, H. H., Ahmed, M. E., \& Aradaib, I. E. (2020). Association of genotype III of dengue virus serotype 3 with disease outbreak in Eastern Sudan, 2019. Virology Journal, 17(1), 1-8.

Fares, R. C., Souza, K. P., Añez, G., \& Rios, M. (2015). Epidemiological scenario of dengue in Brazil. BioMed research international, 2015.

Figueiredo, L. T. M. (2007). Emergent arboviruses in Brazil. Revista da Sociedade Brasileira de Medicina Tropical, 40, $224-229$.

Go, Y. Y., Balasuriya, U. B., \& Lee, C. K. (2014). Zoonotic encephalitides caused by arboviruses: transmission and epidemiology of alphaviruses and flaviviruses. Clinical and experimental vaccine research, 3(1), 58-77.

Gonçalves, B. D. S., Nogueira, R. M. R., Bispo de Filippis, A. M., \& Horta, M. A. P. (2019). Factors predicting the severity of dengue in patients with warning signs in Rio de Janeiro, Brazil (1986-2012). Transactions of The Royal Society of Tropical Medicine and Hygiene, $113(11), 670-677$.

Gubler, D. J. (2002). The global emergence/resurgence of arboviral diseases as public health problems. Archives of medical research, 33(4), 330-342.

Guzman, M. G., \& Harris, E. (2015). Dengue. The Lancet, 385(9966), 453-465.

Guzman, M. G., Gubler, D. J., Izquierdo, A., Martinez, E., \& Halstead, S. B. (2016). Dengue infection. Nature reviews Disease primers, $2(1)$, 1-25.

Guzman, M. G., Halstead, S. B., Artsob, H., Buchy, P., Farrar, J., Gubler, D. J., \& Peeling, R. W. (2010). Dengue: a continuing global threat. Nature reviews microbiology, 8(12), S7-S16.

Heinz, F. X., \& Stiasny, K. (2012). Flaviviruses and flavivirus vaccines. Vaccine, 30(29), 4301-4306.

Hu, Y., Xi, Z., Liu, X., Wang, J., Guo, Y., Ren, D., \& Liu, Q. (2020). Identification and molecular characterization of Wolbachia strains in natural populations of Aedes albopictus in China. Parasites \& vectors, 13(1), 1-14.

Jerome, H., Taylor, C., Sreenu, V. B., Klymenko, T., Filipe, A. D. S., Jackson, C., \& Thomson, E. C. (2019). Metagenomic next-generation sequencing aids the diagnosis of viral infections in febrile returning travellers. Journal of Infection, 79(4), 383-388.

Johnson, N., Voller, K., Phipps, L. P., Mansfield, K., \& Fooks, A. R. (2012). Rapid molecular detection methods for arboviruses of livestock of importance to northern Europe. Journal of Biomedicine and Biotechnology, 2012.

Kar, M., Nisheetha, A., Kumar, A., Jagtap, S., Shinde, J., Singla, M., \& Medigeshi, G. R. (2019). Isolation and molecular characterization of dengue virus clinical isolates from pediatric patients in New Delhi. International Journal of Infectious Diseases, 84, S25-S33.

Kyle, J. L., Harris, E. (2008) Global spread and persistence of dengue. Annual review of microbiology,62, 71-92.

Lanciotti, R. S., Calisher, C. H., Gubler, D. J., Chang, G. J., \& Vorndam, A. V. (1992). Rapid detection and typing of dengue viruses from clinical samples by using reverse transcriptase-polymerase chain reaction. Journal of clinical microbiology, 30(3), 545-551.

Lau, Y. L., Lai, M. Y., Teoh, B. T., Abd-Jamil, J., Johari, J., Sam, S. S., \& AbuBakar, S. (2015). Colorimetric detection of dengue by single tube reversetranscription-loop-mediated isothermal amplification. PloS one, 10(9), e0138694.

Lopes, N., Nozawa, C., \& Linhares, R. E. C. (2014). Características gerais e epidemiologia dos arbovírus emergentes no Brasil. Revista Pan-Amazônica de Saúde, 5(3), 10-10.

Mansuy, J. M., Lhomme, S., Cazabat, M., Pasquier, C., Martin-Blondel, G., \& Izopet, J. (2018). Detection of Zika, dengue and chikungunya viruses using single-reaction multiplex real-time RT-PCR. Diagnostic microbiology and infectious disease, 92(4), $284-287$.

Mendonça, M. C. L. D., Mares-Guia, M. A., Rodrigues, C. D. D. S., Santos, C. C. D., Chalhoub, F. L. L., Araújo, E. S. M., \& Filippis, A. M. B. D. (2018). Imported case of Dengue virus 3 genotype I in Rio de Janeiro state, Brazil. Memórias do Instituto Oswaldo Cruz, 113.

Ministério da saúde. (2020). Monitoramento dos casos de arboviroses urbanas transmitidas pelo Aedes Aegypti (dengue, chikungunya e Zika), Semanas Epidemiológicas 01 a 52. Boletim Epidemiológico, 51 (02), 1-5. Recuperado 5 jan. 2021, de: https://antigo.saude.gov.br/images/pdf/2020/janeiro/20/Boletimepidemiologico-SVS-02-1-.pdf

Ministério da saúde1. (2020). Monitoramento dos casos de arboviroses urbanas transmitidas pelo Aedes Aegypti (dengue, chikungunya e zika), semanas epidemiológicas 1 a 46 . Boletim Epidemiológico, $51 \quad$ (48), 1-7. https://www.gov.br/saude/pt-br/media/pdf/2020/dezembr o/11/boletim_epidemiologico_svs_48.pdf

Moreli, M. L., \& Costa, V. G. (2013). A systematic review of molecular diagnostic methods for the detection of arboviruses in clinical specimens in Brazil and the importance of a differential diagnosis. Virology Discovery, $1(1), 1$. 
Mun, M. J., Bae, J. Y., Kim, J. H., Kim, S. B., Lee, I., Kim, J. I., \& Nam, Y. S. (2019). One-step multiplex real-time RT-PCR for detection and typing of dengue virus. Molecular and cellular probes, 43, 86-91.

Neeraja, M., Lakshmi, V., Lavanya, V., Priyanka, E. N., Parida, M. M., Dash, P. K., \& Reddy, G. (2015). Rapid detection and differentiation of dengue virus serotypes by NS1 specific reverse transcription loop-mediated isothermal amplification (RT-LAMP) assay in patients presenting to a tertiary care hospital in Hyderabad, India. Journal of virological methods, 211, 22-31.

Pateu, P., Landt, O., Kaiser, M., Faye, O., Koppe, T., Lass, U., \& Niedrig, M. (2013). Development of one-step quantitative reverse transcription PCR for the rapid detection of flaviviruses. Virology journal, 10(1), 1-11.

Peeling, R. W., Artsob, H., Pelegrino, J. L., Buchy, P., Cardosa, M. J., Devi, S., \& Yoksan, S. (2010). Evaluation of diagnostic tests: dengue. Nature Reviews Microbiology, 8(12), S30-S37.

Perry, J. W., \& Tai, A. W. (2018). Random Insertional Mutagenesis of a Serotype 2 Dengue Virus Clone. Bio-protocol, 8(16).

Prajapati, S., Napit, R., Bastola, A., Rauniyar, R., Shrestha, S., Lamsal, M., \& Manandhar, K. D. (2020). Molecular phylogeny and distribution of dengue virus serotypes circulating in Nepal in 2017. PloS one, 15(7), e0234929.

Queiroz, J. A. D. S., Botelho-Souza, L. F., Nogueira-Lima, F. S., Rampazzo, R. D. C. P., Krieger, M. A., Zambenedetti, M. R., \& Santos, A. D. O. D. (2020). Phylogenetic Characterization of Arboviruses in Patients Suffering from Acute Fever in Rondônia, Brazil. Viruses, 12(8), 889.

Ramos-Castaneda, J., Barreto dos Santos, F., Martinez-Vega, R., Galvão de Araujo, J. M., Joint, G., \& Sarti, E. (2017). Dengue in Latin America: systematic review of molecular epidemiological trends. PLoS neglected tropical diseases, 11(1), e0005224.

Ratnam, I., Leder, K., Black, J., \& Torresi, J. (2013). Dengue fever and international travel. Journal of travel medicine, 20(6), 384-393.

Ribeiro, V, S, T., Telles, J, P., Tuon, F. F. (2020). Arboviral diseases and COVID-19 in Brazil: Concerns regarding climatic, sanitation, and endemic scenario. Journal of medical virology, 92(11), 2390-2391.

Rico-Hesse, R. (2003). Microevolution and virulence of dengue viruses. Advances in virus research, $59,315$.

Rodrigues, H. S., Souza, R. P., de Sousa, R. W. R., Pereira, L. C. A., Branco, R. R. D. O. C., Silveira, P. H. F. P., \& Britto, M. H. R. M. (2020). Perfil de interações medicamentosas de Agentes Antineoplásicos Orais (AAOs) dispensados para pacientes oncológicos. Research, Society and Development, 9(8), e145985369-e145985369.

Santiago, G. A., Vázquez, J., Courtney, S., Matías, K. Y., Andersen, L. E., Colón, C., \& Muñoz-Jordan, J. L. (2018). Performance of the Trioplex real-time RT-PCR assay for detection of Zika, dengue, and chikungunya viruses. Nature communications, 9(1), 1-10.

Seshan, V., Sarangan, G., Sheriff, K., Krishnasamy, K., Palani, G., \& Srikanth, P. (2017). Serological, molecular and clinical correlates of dengue from a tertiary care centre in Chennai, India. Archives of virology, 162(10), 2983-2988.

Silva, M. B. A., Brito, M. I. B., Silva, J. M., Barreto, J. O. F., Lopes, K. A. M., Vasconcelos, L. L. E., Santos, T. M. M., Oliveira, K. S. F. (2021) Perfil das arboviroses Dengue, Chikungunya e Zika no Distrito Sanitário III do município de Recife (Brasil). Revista Brasileira de Meio ambiente. 9(1), 39-50.

Sim, S., \& Hibberd, M. L. (2016). Genomic approaches for understanding dengue: insights from the virus, vector, and host. Genome biology, 17(1), 1-15.

Slavov, S. N., Ferreira, F. U., Rodrigues, E. S., Gomes, R., Covas, D. T., \& Kashima, S. (2019). Simultaneous zika and dengue serotype-4 viral detection and isolation from a donor plasma unit. Journal of vector borne diseases, 56(2), 166.

Stubbs, S. C., Blacklaws, B. A., Yohan, B., Yudhaputri, F. A., Hayati, R. F., Schwem, B., \& Frost, S. D. (2020). Assessment of a multiplex PCR and Nanopore-based method for dengue virus sequencing in Indonesia. Virology journal, 17(1), 1-13.

Sucipto, T. H., Kotaki, T., Mulyatno, K. C., Churrotin, S., Labiqah, A., Soegijanto, S., \& Kameoka, M. (2018). Phylogenetic Analysis of Dengue Virus in Bangkalan, Madura Island, East Java Province, Indonesia. Journal of tropical medicine, 2018.

Suwanmanee, S., Surasombatpattana, P., Soonthornworasiri, N., Hamel, R., Maneekan, P., Missé, D., \& Luplertlop, N. (2018). Monitoring arbovirus in Thailand: Surveillance of dengue, chikungunya and zika virus, with a focus on coinfections. Acta tropica, 188, $244-250$.

Terzian, A. C. B., Mondini, A., de Moraes Bronzoni, R. V., Drumond, B. P., Ferro, B. P., Cabrera, E. M. S., \& Nogueira, M. L. (2011). Detection of Saint Louis encephalitis virus in dengue-suspected cases during a dengue 3 outbreak. Vector-Borne and Zoonotic Diseases, 11(3), 291-300.

Weaver, S. C., \& Reisen, W. K. (2010). Present and future arboviral threats. Antiviral research, 85(2), 328-345.

Weaver, S. C., \& Vasilakis, N. (2009). Molecular evolution of dengue viruses: contributions of phylogenetics to understanding the history and epidemiology of the preeminent arboviral disease. Infection, genetics and evolution, 9(4), 523-540.

World Health Organization, Special Programme for Research, Training in Tropical Diseases, World Health Organization. Department of Control of Neglected Tropical Diseases, World Health Organization. Epidemic, \& Pandemic Alert. (2009). Dengue: guidelines for diagnosis, treatment, prevention and control. World Health Organization.

Wu, W., Wang, J., Yu, N., Yan, J., Zhuo, Z., Chen, M., \& Xia, N. (2018). Development of multiplex real-time reverse-transcriptase polymerase chain reaction assay for simultaneous detection of Zika, dengue, yellow fever, and chikungunya viruses in a single tube. Journal of medical virology, 90(11), $1681-1686$. 